\title{
Pleurodesis with Thulium Cyber Laser versus talc poudrage: a comparative experimental study
}

\author{
Andrea Droghetti ${ }^{1}$. Jacopo Vannucci ${ }^{2}$ - Antonello Bufalari ${ }^{3}$. Guido Bellezza ${ }^{4}$. \\ Valentina De Monte ${ }^{3}$ - Giuseppe Marulli ${ }^{5}$ Maria Caterina Bottoli ${ }^{1}$. \\ Michele Giovanardi $^{1}$ • Niccolò Daddi ${ }^{7}$ - Verena De Angelis ${ }^{6} \cdot$ Franco Moriconi $^{3}$. \\ Francesco Puma ${ }^{2}$
}

Received: 20 February 2015 / Accepted: 15 June 2016

(C) Springer-Verlag London 2016

\begin{abstract}
Sclerosing fluids to achieve pleurodesis could be hardly replaced for bed-side procedures, but other devices may be successfully applied during thoracoscopy. Thulium Cyber Laser was experimented for this purpose and compared to talc poudrage. Twenty pigs underwent operative videothoracoscopy (VATS). Ten models were subjected to double-port VATS and parietal pleura photoevaporation using Thulium Cyber Laser ${ }^{\mathrm{TM}}$ (TCL) $150 \mathrm{~W} 2010 \mathrm{~nm}$ on the posterior third of three ribs; the pleural surface was homogeneously treated inside the target perimeter. The remaining ten pigs underwent uniportal thoracoscopy; talc poudrage was performed using the current clinical practice dosage $(1 \mathrm{~g} / 18 \mathrm{~kg})$ with accurate talc powder spread over the whole pleural surface. All models were followed up for 60 days. Pleurodesis firmness was graded on a three-tier scale (none-moderate-
\end{abstract}

Andrea Droghetti and Jacopo Vannucci contributed equally to this work.

Andrea Droghetti

adroghetti@libero.it

1 Thoracic Surgery Division, Carlo Poma Hospital, via Lago Paiolo $\mathrm{n}^{\circ} 10,46100$ Mantova, Italy

2 Thoracic Surgery Unit, University of Perugia Medical School, Perugia, Italy

3 Department of Veterinary Medicine, University of Perugia, Perugia, Italy

4 Institute of Pathological Anatomy and Histology, University of Perugia Medical School, Perugia, Italy

5 Thoracic Surgery Division, University of Padova, Padova, Italy

6 Medical Oncology Division, Santa Maria della Misericordia Hospital, Perugia, Italy

7 Thoracic Surgery, Department of Medical and Surgical Sciences (DIMEC), Alma Mater Studiorum, University of Bologna, Bologna, Italy firm) and site-matching topographical expectancy was evaluated. TCL produced pleurodesis in all models: 7/10 were firm and 3/10 moderate. Talc poudrage pleurodesis was firm in 4/ 10 and moderate in 6/10. Pleural adhesions were found exclusively in the treated area after laser treatment, while talc created a wide spectrum of effects, most commonly anarchic jagged adhesions obliterating less than $50 \%$ of the pleural cavity (7/10), mostly declivous. The pathologist found more aggressive inflammation (sometimes severe) in the talc group. Expected localized pleurodesis was always registered in laser group (10/10), while talc poudrage was found poorly effective if consistent pleurodesis is expected in an apico-dorsal position $(2 / 10)$. Laser pleurodesis appears more homogeneous, qualitatively not inferior, and topographically more predictable than talc pleurodesis. Parietal photoevaporation seems effective and the localized pleurodesis is reproducible.

Keywords Pleurodesis · Pleural disease · Pneumothorax · Videothoracoscopy $\cdot$ Laser $\cdot$ VATS

\section{Introduction}

The search for the ideal sclerosing substance has developed a number of studies, progressively improving the spectrum of medication offered for intrapleural injection [1,2]. Although bed-side procedure is the most common when attempting at pleural cavity obliteration, pleurodesis is often indicated during thoracoscopy. In this setting, the possible management encompasses further options for nonchemical devices [3]. Mechanical and physical tools have been traditionally thought to be of less interest than chemical products, but they sometimes show a competitive risk/effectiveness balance [4]. Indeed, chemical agents have revealed some side or systemic effects, while physical devices are reported to be safer [5]. 
Furthermore, in certain diseases such as pneumothorax, it is preferable to obtain localized, targeted pleurodesis rather than a complete pleural symphysis [6].

If we consider the supreme features of a pleurodesis agent, we see that there is currently no one which suits every situation and research should focus not only on the discovery of the "ideal substance" but also on the appropriateness of using the already available instruments $[1,2]$. For this reason, the technique for efficient and riskless pleurodesis needs to be tailored on specific clinical, prognostic, demographic, and pathological standpoints.

Clinical practice showed pleurodesis potential for Thulium Cyber Laser (TCL) photoevaporation that has been experimentally tested in order to hypothesize effectiveness and eventual clinical application. TCL operates at wavelength of 1930-2040 nm and proved to be suitable for superficial tissue ablation [7]. The aim of this study is to compare reliability, efficacy, and quality of thoracoscopic pleurodesis with TCL versus talc poudrage in normal pleural cavity of large animal model, simulating nonmalignancy-related indication for pleural space obliteration (i.e., pneumothorax).

\section{Materials and methods}

\section{Animal experiment}

The study protocol was evaluated and approved by local and national Authorities for Ethics and Animal Care.

Ten 40-45 kg Landrace $\times$ Large White pigs (Sus scrofa domesticus) were subjected to operative videothoracoscopy (experimental group); a homogeneous group of other 10 pigs underwent videothoracoscopic talc poudrage (control group). Talc poudrage was chosen for the control group because it is definitely the most employed pleurodesis agent worldwide. Despite it is imperfect, often disputed or even categorically refused by some physicians for specific indications, talc remains the most common medical solution and, generally preferred over the other available materials, to obliterate the pleural space.

Pigs were transferred to the experimental center 1 week before operation for environmental acclimatization, and they were controlled daily during the preoperative period to rule out eventual unexpected disease. All animals have received human standard care in compliance with the "Guide for the Care and Use of Laboratory Animals." The eighth edition was published by the National Institutes of Health (NIH publication, 1996). We chose the Landrace $\times$ Large White pigs for the following reasons: it is a species approved as a laboratory animal by our national law, is easy to stall, has a favorable anatomy, and is not expensive. Preoperative antibiotic prophylaxis was performed intramuscularly. Animals were premedicated with ketamine ( $8 \mathrm{mg} / \mathrm{kg}$; Ketavet 100, Intervet), methadone $(0.2 \mathrm{mg} /$ $\mathrm{kg}$; Eptadone, Molteni Farmaceutici), and dexmedetomidine
(20 $\mu \mathrm{g} / \mathrm{kg}$; Dexdomitor, Elanco Animal Health) intramuscularly behind the ear. Anesthesia was induced with propofol (4 $6 \mathrm{mg} / \mathrm{kg}$, Proposure, Merial) and trachea was intubated with a $7-7.5-\mathrm{mm}$ cuffed tube. General anesthesia was maintained using sevoflurane (SevoFlo, Abbott) in oxygen or by a constant rate infusion of propofol $(0.1-0.5 \mathrm{mg} / \mathrm{kg} / \mathrm{min})$ and $\mathrm{O}_{2}$. The animals were mechanically ventilated. A constant rate infusion of sufentanyl $(0.1-0.5 \mu \mathrm{g} / \mathrm{kg} / \mathrm{h}$; Sufentanil-Hameln, Hospira) was started just before surgery and a bolus of $0.1 \mu \mathrm{g} / \mathrm{kg}$ was given if signs of pain were shown. The heart rate, respiratory rate, pulse rate, peripheral oxygen saturation, invasive blood pressure, airways pressure, gas inspiration and expiration or propofol infusion, tidal volume, and body temperature were continuously monitored and recorded every 5 min.

The camera entered the chest (11.5 $\mathrm{mm}$ trocar, IX intecostal space) in order to have the pleural cavity evaluated for possible adhesions (in the case of pleural adhesions, the pig would have been excluded from the study). One 15-mm operative port was created under endoscopic view ventrally in the $\mathrm{V}$ intercostal space just behind the shoulder to simulate the circumstance of a double-port operative videothoracoscopy usually employed in those diseases requiring surgery and pleurodesis. The lung was actively deflated by gentle sponge pressure, and the posterior chest wall was exposed. Costal arches were counted to identify the fourth, fifth, and sixth ribs. A TCL unit (Quanta System S.p.A. Solbiate Olona, VA, Italy) was employed for pleurodesis using a disposable laser fiber $(550 \mathrm{~nm})$ with $40-\mathrm{W}$ energy setting. The laser beam delivery system was inserted through the operative port and placed about $3 \mathrm{~cm}$ from the dorsal rib cage. A median of $6871.50 \pm$ 417-J laser energy was delivered to the targeted area. Laser scarification was homogeneously performed to obtain coagulation of the parietal pleura vessels and complete serous sheet drying through continuous burn up to carbonization. Laser energy was administered until visual feedback of pleural shrinking, translucency loss, progressive opacification, and a brownish look was obtained; the energy setting of $40 \mathrm{~W}$ allowed appropriate treatment besides easily avoiding damage or penetration to endothoracic fascia and muscular layer. Once this effect was precisely obtained, the TCL was addressed to the contiguous pleural spot. Treatment was targeted to the posterior third of fourth, fifth, and sixth costal arches. Pleural cavity was then put under $-15 \mathrm{~cm} \mathrm{H}_{2} \mathrm{O}$ suction by means $24 \mathrm{Ch}$ catheter.

All instruments except the camera were thus pulled out of the chest, and the anesthesiologist was asked to inflate the lungs by progressive positive pressure to solve possible atelectasis. Pleural suction was maintained until complete pressure negativity was reestablished. Incisions were sutured only after complete pneumothorax resolution. In the case of doubt or deficiency, the procedure to achieve complete lung reexpansion was repeated. 
A $15-\mathrm{mm}$ incision was placed in the mid-chest of control group pigs, and the camera was inserted for examination of the pleural cavity. Talc poudrage was performed according to the current clinical practice guidelines and adapted to model's dimensions (1 g/18 kg). The quantum of dry, sterile depurated talc with graded particles of 25- $\mu \mathrm{m}$ diameter (Steritalc, Novatech SA, La Ciotat, France) was administered by regular disposable insufflator. The procedure follows British Thoracic Society (BTS) latest update [8]. The camera was returned into the cavity to visually control that dry talc powder had spread evenly all over the pleural surface with homogeneous and extensive contact between pleurae and sclerosant to avoid spotted deposit and slurry-like pattern. The same technique for pneumothorax resolution which was applied to the Laser group was also used before closure of the incision in the Talc group.

The pigs were then hospitalized in swine-specific single boxes where they were kept for 60 days. Medical evaluation was performed twice a day for the first week and then once a day until postoperative day 60 [9]. The pigs were sacrificed according to painless euthanasia protocol (tiletamine/zolazepam $7 \mathrm{mg}$ / kg IM; thiopental $1 \mathrm{~g}$ IV; embutramide $200 \mathrm{mg}$, mebenzonium iodide $50 \mathrm{mg}$, tetracaine chloride $5 \mathrm{mg}$ IV), and carcasses were evaluated by the same surgical team.

\section{Pleurodesis scoring scale}

Pleurodesis was graded according to the following three definitions:

1. None: no adhesion or an adhesion which breaks when pneumothorax is created or adhesions that do not impede the collapse of the lung. No functional/therapeutic significance.

2. Moderate: an adhesion which prevents air/fluids accumulation, pleural sheets are recognizable, soft connective tissue is interposed between pleurae. Pleurodesis (simple adhesion or symphysis) in less than $50 \%$ of the treated area.

3. Firm: pleural sheets are not recognizable (symphysis) or visible but contiguous. No space or floppy tissue is interposed between pleurae. Pleural space is completely obliterated.

This three-tier scale was extrapolated from the most commonly employed grading scale developed by Gary Lee et al. [10] and Kuschel et al. [11]. These scales focus on different aspects: firmness, extent of the adhesion, and compliance to surgical manipulation so defining passive resistance to air/ fluid accumulation. Firmness is described by Gary Lee et al. [10] in three levels: (1) no adhesions, (2) adhesions with no symphysis, and (3) adhesions with symphysis. Each of these levels has subranks (eight total levels) describing the surface of obliterated pleural space, but such a category is not fitting for potential locoregional pleurodesis. We therefore applied the firmness grouping with Gary Lee et al.'s scale after its adaptation, but we dismissed the remaining part on the surface extent. Adhesion compliance or resistance to surgical manipulation is adopted according to Kuschel [11]. Therefore, talc pleurodesis was evaluated through both scales to allow a thorough evaluation of talc action. Surgical specimens were fixed in $10 \%$ buffered formalin and embedded in paraffin wax. Serial sections $(4 \mu \mathrm{m})$ were stained with hematoxylin and eosin. The pathologist was asked to report on specific issues like inflammation, fibrosis, visceral and parietal pleurae thickness, foreign body presence, and related tissue reaction.

\section{Preliminary methodology assessment}

Before starting, the method was validated. In three pigs, $50 \mathrm{ml}$ of $\mathrm{NaCl} 0.9 \%$ sterile isotonic solution was injected into the pleural cavity through a $15-\mathrm{mm}$ thoracoscopic port. A chest X-ray was performed soon after surgery in still sedated but spontaneously breathing animals to ensure complete pneumothorax resolution. After 60 days, the chest cavity was controlled by videothoracoscopy in the euthanized animals. No sign of postinflammatory reaction could be detected in any of the three models. The finding of completely free pleural space demonstrated that the surgical procedure, porcine biology, and the postoperative method of animal maintenance did not create by themselves any kind of pleural adhesion after the course of 60 days without clinical events.

\section{Statistical analysis}

Descriptive statistics were expressed as median (range) or as mean \pm SD or percentages, as appropriate. Categorical data were compared using Fisher's exact test. Continuous variables were analyzed by Wilcoxon rank-sum test and with Spearman correlation. All statistical analyses were performed by a medical statistician using SPSS version 16 (SPSS, Inc., Chicago, IL). Throughout the analysis, $P<0.050$ was considered to represent statistical significance. The sample size was calculated according to the following considerations: a prospective trial with correlated responses within pairs groups, alpha $=$ 0.05 , power $=0.8, P_{0}=0.4, P_{1}=0.8$, and $\Phi=0.3$ required a number of nine pairs of pigs. The sample size has been increased by $10 \%$ for any possible unexpected need $\left[P_{0}=\right.$ the event rate (area sclerosant contact/area of adhesion $>50 \%$ ) among controls; $P_{1}=$ the event rate among cases].

\section{Results}

A pig was replaced as preexisting pleural adhesions were found during the exploratory phase of the thoracoscopy. Clinical records were preliminarily evaluated in order to 
ascertain whether the experimental findings could have been spoiled by other events. No pigs had surgery-related complications. No episode of systemic disease appeared. No respiratory, behavioral, or feeding disorder was registered. Each model's growth rate was within the normal range. No difference emerged between the two groups for clinical and morphometric parameters.

TCL photoevaporation produced pleurodesic effects in 10/ 10 models (Table 1). The dosimetric panel highlights that the treatment was performed in a median delivery time of $178^{\prime \prime}$ (range 68-221, mean 164.80), and the median delivered energy was $6871.50 \mathrm{~J}$ (range 6320-7180, mean 6711.20). The surgery's time-span only varies for the time due to laser energy delivery that is expected to be no more than $9^{\prime}$ to theoretically treat all the visible costal arches, while talc poudrage is faster (almost instantaneous). Postmortem analysis showed no signs of reaction other than on the treated site. Untreated parietal pleura appeared normal everywhere with no pleural effusion, no diffuse hyperemia, or thickenings in 10/10 pigs. Lungs appeared normal in terms of color, shape, consistence, and homogeneity; visceral pleura did not show any kind of thickening, opacity, or inhomogeneity (except the treated area). A mechanical test of pulling the lung away from chest wall demonstrated consistent pleuro-pulmonary adhesion representing reliable medical pleurodesis in all models. Further macroscopic analysis categorized 7/10 firm adhesions with symphysis and $3 / 10$ moderate adhesions with no symphysis. Adhesion in less than $50 \%$ of the treated surface was never found; therefore, tissue density was the real determinant for the grading classification. Although laser target-surface and postmortem findings are overlapping, minimal but evident subareas of different levels of adhesion density were observed. The final category was given according to the predominant feature (Fig. 1).

Talc poudrage produced pleurodesis effects in 10/10. There were 4/10 firm results and 6/10 moderate; the distribution of results according to Gary Lee's scale describes a very variable outcome of talc pleurodesis (Table 1).
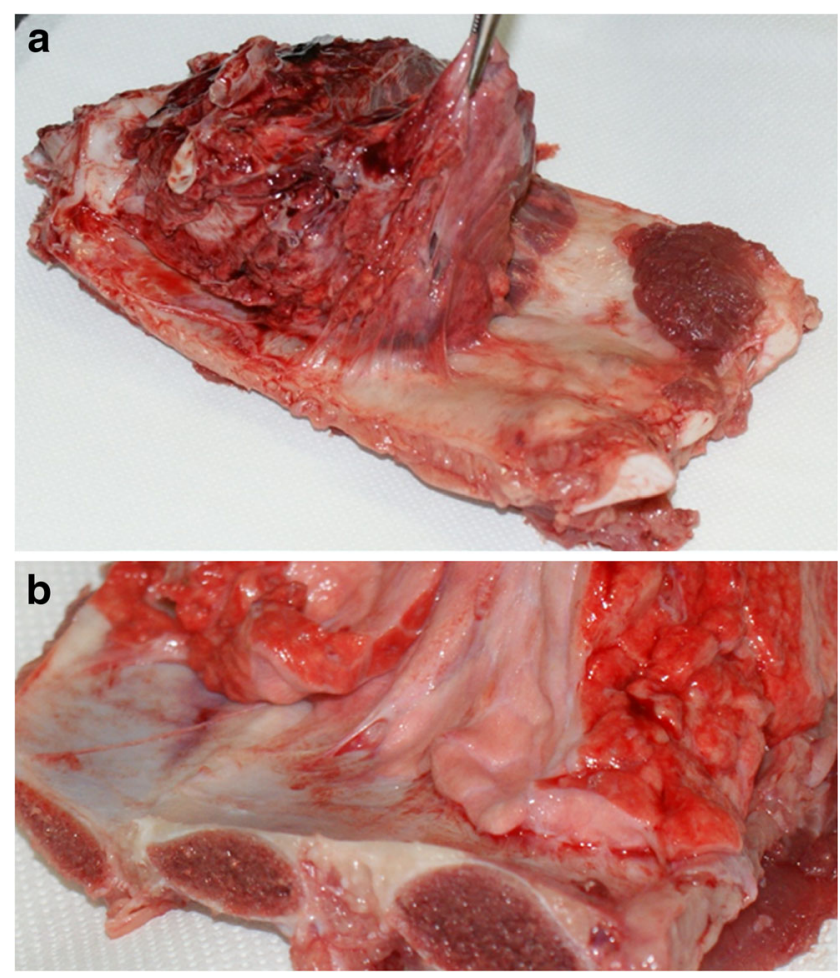

Fig. 1 Thulium Cyber Laser treatment. Adhesion is found all over the treated surface and testified by lung pulling (a). Particular view of pleurodesis (b). Lung appears normal, parietal pleura is healthy, and there is no active inflammatory process

Data analysis showed that pleurodesis appeared in the expected site (area where the pleura and sclerosing agent had contact) in 10/10 pigs in TCL group, while it happened in $1 / 10$ pig in talc group (talc is spread all over the pleural surface after poudrage, so complete pleural cavity obliteration is the ideal target, pig 17); moreover, adhesion in anti-declivous position is registered in 2/10 talc procedures. All the other models showed pleurodesis of less than $50 \%$ of pleural cavity in declivous position. Specific comparative outcome concerning pleurodesis category, topographical concordance, and upper

Table 1 Thulium Cyber Laser pleurodesis (1-10) and Talc pleurodesis (11-20)

\begin{tabular}{llllllll}
\hline Model no. & Pleurodesis grade & $\begin{array}{l}\text { Topographical } \\
\text { concordance }\end{array}$ & $\begin{array}{l}\text { Complete targeted } \\
\text { apico-dorsal effect }\end{array}$ & Model no. & $\begin{array}{l}\text { Pleurodesis grade } \\
\text { (Gary Lee's scale) }\end{array}$ & $\begin{array}{l}\text { Pleural cavity } \\
\text { obliteration }>50 \%\end{array}$ & $\begin{array}{c}\text { Apico-dorsal adhesion } \\
1\end{array}$ \\
\hline & Moderate & + & + & 11 & Moderate (2/8) & - & - \\
2 & Firm & + & + & 12 & Moderate (4/8) & - & - \\
3 & Firm & + & + & 13 & Moderate (2/8) & - & - \\
4 & Firm & + & + & 14 & Firm (7/8) & + & + \\
5 & Firm & + & + & 15 & Firm (7/8) & + & - \\
6 & Moderate & + & + & 16 & Moderate (2/8) & - & - \\
7 & Firm & + & + & 17 & Firm (8/8) & + & - \\
8 & Firm & + & + & 18 & Moderate (3/8) & - & - \\
9 & Moderate & + & + & 19 & Moderate (3/8) & - & - \\
10 & Firm & + & + & 20 & Firm (5/8) & - & - \\
\hline
\end{tabular}


Table 2 Statistical analysis

\begin{tabular}{llll}
\hline & Laser group & Talc group & $p$ \\
\hline Pleurodesis category, firm-moderate/total & $7-3 / 10$ & $4-6 / 10$ & n.s. \\
$\begin{array}{l}\text { Topographical correspondence area sclerosant } \\
\quad \text { contact/area of adhesion }>50 \%\end{array}$ & $10 / 10$ & $3 / 10$ & 0.003 \\
Upper chest adhesions (anti-declivous position) & $10 / 10$ & $2 / 10$ & 0.001 \\
\hline
\end{tabular}

chest adhesions is reported in Tables 2 and 3; therefore, TCL creates a predictable circumscribed inflammatory reaction which leads to a locoregional pleurodesis with homogenous tissue features and valuable respect of the surrounding anatomy. Anatomical features of pleurodesis after TCL treatment give the possibility to simply recreate the pleural cavity following recognizable landmarks in an uncomplicated field for surgical dissection (scissors and sponge-on-stick).

The pathologist described full concordance between histological and macroscopic findings: macroscopic firm adhesions were histologically characterized by delicate adhesions between pleurae with some connective tissue intermixed. Fibrosis was partially evident, more greatly represented in firm adhesions than in moderate but photoevaporation left fewer burning effects than expected and the adhesion seemed really respectful of any anatomical structures. Coagulative necrosis was therefore only occasional, and all tissues remained healthy and undamaged with modest hyperemia where it was present. As previously said, the only remarkable effect was the pleural fusion (Fig. 2).

Talc pleurodesis offers different outcome. Pleurae and proximal tissues show some spots cruently involved by talc reaction. The pathologist described an inhomogeneous fibrotic reaction with granulomas, severe inflammation around birefringent small-particled foreign body deposits. Dense scar tissue, talc accruals, and areas of ineffective pleurodesis follow one another in space. Moreover, most pleurodesis after talc poudrage shows vascularized arch-shaped irregular branches of connective tissue once the chest is opened at autopsy. These adhesions alongside spots of aggressive fibrosis represent an important limitation for safe redo surgery.

\section{Discussion}

Laser technology has been fairly widespread in medicine and surgery, although new applications can be explored or revisited in light of new technologies available. The problem of cost/ effectiveness remains a matter of debate: the purchase/ maintenance of a laser medical tool and related apparatus needs optimizing and to be exploited in each potential to guarantee its economical sustainability $[12,13]$. In this context, pleurodesis appears a reasonable possibility for laser technology which has not, thus far, received sufficient enthusiasm to be established as a valuable option. In fact, several studies demonstrated no consistent benefit after parietal pleura coagulation with an Argon beam and other physical tools [14-16]. An experimental study comparing innovative laser to gold standard (talc poudrage) was therefore needed, and we developed this study design in a large animal model in order to minimize the adaptation of surgical procedure and to optimize anatomical proportion between human beings and animal model.

The experimental setting gave the opportunity to evaluate some additional aspects such as the microscopic outline of pleural adhesions, differences in inflammatory reactions, and site-matching results after different sclerosant administration. Moreover, loco-regional features of tailored pleurodesis are compared to talc which has been already disputed for its safety in clinical practice [5] and experimentally found to produce above-normal inflammation and side effects when compared to other fluid agents [17].

TLC proved to be effective in producing loco-regional pleurodesis. There was no evidence of pleural inflammatory reaction anywhere else in the chest away from the treated area,

Table 3 Pleurodesis features

\begin{tabular}{lcc}
\hline Pleurodesis feature & Laser & Talc \\
\hline Agent migration & - & + \\
Matching (area of treatment/pleurodesis site) & + & - \\
Adhesion continuity & + & $+/-$ \\
Adhesion homogeneity & + & - \\
Granuloma, chronic inflammation & - & + \\
Over needed fibrosis & - & + \\
Presence of floppy adhesions (significant for pleurodesis purpose) & $+/-$ \\
\hline
\end{tabular}

Comparison between Laser and Talc 
Fig. 2 Microscopic evaluation. EE $\times 10$ shows normal lung, connective homogeneous tissue forming a reliable adhesion. Few inflammatory cells and no evident coagulative necrosis (a). Pleurodesis is represented by proximal layers of dense connective tissue, but low fibrosis is found (b)

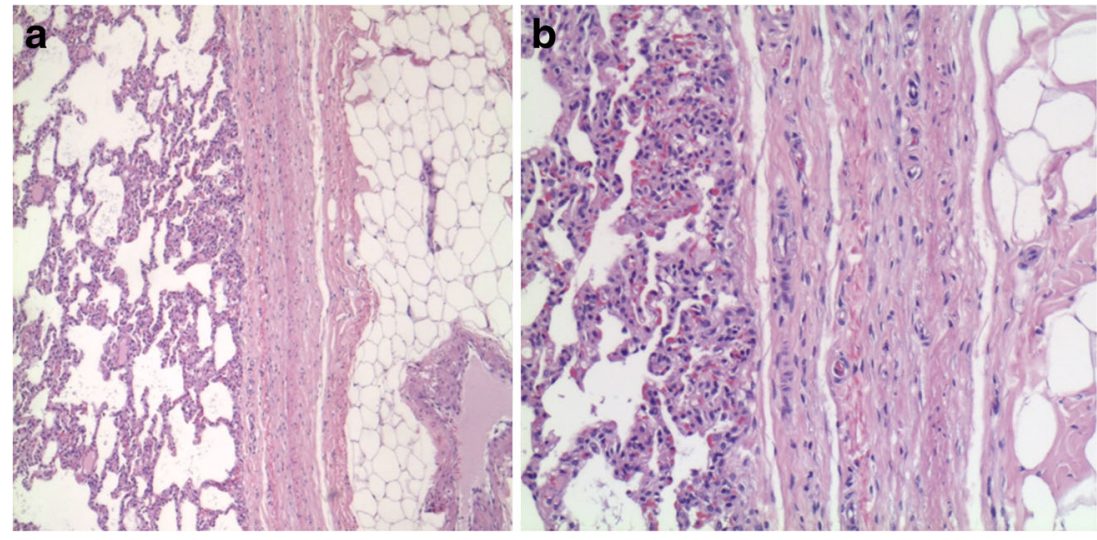

so these results demonstrate that TLC can lead to a tailored pleurodesis by addressing adhesions where required. Considering the model employed in this study, the efficacy in producing effective pleurodesis and repeatability of locoregional outcome give specific translational orientation headed for benign pleural disease as already reported in recent literature [18]. Localized pleurodesis is generally adopted in some clinical settings, mainly for spontaneous pneumothorax [19], and medical lasers have already shown important properties in providing highly accurate finite treatment when required. In case an extended effect is wanted, producing a complete pleural surface treatment has already well described and successfully achieved (Argon beam coagulator) [20], but further research is required to assess risk/benefit.

Histological evaluation highlighted some aspects concerning tissue forming adhesions, inflammatory processes leading to pleurodesis, and tissue array and composition. Chronic inflammatory patterns were not found in the laser group where adhesion layout is homogenous and respectful of anatomical layers, while talc poudrage determines different foci of irritative reaction with hyperemia and active inflammation at the 60th postoperative day. The presence of talc powder over the pleural surface was spotted at autopsy. Indeed, talc was not found homogeneously spread over all the pleural surface as when it was administered during poudrage; the finding of evident talc deposits demonstrates talc migration, especially to declivous position. Powder migration consistently results in adhesions forming in declivous position rather than superiorly.

The most remarkable aspect of this comparative study concerns the quality of pleurodesis specifically regarding differences between adhesion tissue features: TCL generates reliable pleurodesis in which inflammation is resolved after 60 days; moreover, TCL pleurodesis shows a consistently homogeneous pattern of symphysis without granulomas, foreign bodies, or florid inflammation. Besides, talc pleurodesis shows jagged adhesions with spotted inflammation with occasional notable angiogenesis, clusters of granulomas. Additionally, the lack of shrinking fibrosis, florid inflammation, and hypervascularized adhesions gives TCL the potentially important attribute of easier restoration of the pleural cavity by following a favorable and more clear anatomical field in the case of reoperation.

Certainly, the small sample size reduces the statistical power of our study, and further investigations are required. However, our results suggest that $-\mathrm{TCL}$ can produce a reliable pleurodesis in a targeted area, without causing diffuse pleural inflammation and -talc generates pleurodesis with a limited propensity for the anti-declivous position, because of powder migration due to gravity.

Potential translation into clinical practice can be hypothesized. Talc should not be recommended in spontaneous pneumothorax for pleurodesis considering the possible side effects, chronic evolution of inflammation, and powder migration; recurrent pneumothorax benefits from apical pleurodesis and powder migration does not guarantee the required result, while TCL has a full correspondence between site of treatment and pleurodesis area. Pleural effusion may lead to a washout effect after talc usage, especially talc slurry. When videothoracoscopy is required, pleural photoevaporation can potentially reduce effusion production and is not affected by washing out.

Acknowledgments The study was supported by a free donation from Quanta System S.p.A. Solbiate Olona, VA, Italy. The authors acknowledge the invaluable work of all our fellows and the outstanding participation of Tiziana Zambon. Special thanks to all technical assistants especially Mariano Rosati for his devotion for animal care.

\section{Compliance with ethical standards}

Conflict of interest Authors declare no conflict of interest.

\section{References}

1. Light RW (2013) Pleural diseases, 6th edn. Lippincott, Williams and Wilkins, Baltimore

2. Light RW (2013) New agents for pleurodesis. Curr Respir Care Rep 2:88-92

3. Marcheix B, Renaud C, Lamarche Y, Mugniot A, Benouaich V, Berjaud J, Dahan M (2007) Videothoracoscopic silver nitrate pleurodesis for primary spontaneous pneumothorax: an alternative 
to pleurectomy and pleural abrasion? Eur J Cardiothorac Surg 31(6):1106-1109

4. Bresticker MA, Oba J, LoCicero J 3rd, Greene R (1993) Optimal pleurodesis: a comparison study. Ann Thorac Surg 55:364-366

5. Light RW (2000) Talc should not be used for pleurodesis. Am J Respir Crit Care Med 162(6):2024-2026

6. Gossot D, Galetta D, Stern JB, Debrosse D, Caliandro R, Girard P, Grunenwald D (2004) Results of thoracoscopic pleural abrasion for primary spontaneous pneumothorax. Surg Endosc 18(3):466-471

7. Duarte FJ (2008) Tunable laser applications. CRC Press, Boca Raton, p214. ISBN 1-4200-6009-0.

8. Maskell N, British Thoracic Society Pleural Disease Guideline Group (2010) British Thoracic Society Pleural Disease Guidelines - 2010 update. Thorax 65(8):667-669

9. Bufalari A, De Monte V, Pecoriello R, Donati L, Ceccarelli S, Cagini L, Ragusa M, Vannucci J (2015) Experimental left pneumonectomy in pigs: procedure and management. J Surg Res 198(1):208-216

10. Gary Lee YC, Melkerneker D, Thompson PJ, Light RW, Lane KB (2002) Transforming growth factor beta induces vascular endothelial growth factor elaboration from pleural mesothelial cells in vivo and in vitro. Am J Respir Crit Care Med 165(1):88-94

11. Kuschel TJ, Gruszka A, Hermanns-Sachweh B, Elyakoubi J, Sachweh JS VJS, Vhhw J, Sa JF, Schnoering H (2013) Prevention of postoperative pericardial adhesions with TachoSil. Ann Thorac Surg 95(1):183-188

12. Neumann PJ, Weinstein MC (2010) Legislating against use of costeffectiveness information. N Engl J Med 363(16):1495-1497

13. Marulli G, Droghetti A, Di Chiara F, Calabrese F, Rebusso A, Perissinotto E, Muriana G, Rea F (2013) A prospective randomized trial comparing stapler and laser techniques for interlobar fissure completion during pulmonary lobectomy. Lasers Med Sci 28(2):505-511

14. Sepehripour AH, Nasir A, Shah R (2012) Does mechanical pleurodesis result in better outcomes than chemical pleurodesis for recurrent primary spontaneous pneumothorax? Interact Cardiovasc Thorac Surg 14(3):307-311

15. Bobbio A, Ampollini L, Internullo E, Caporale D, Cattelani L, Bettati S, Carbognani P, Rusca M (2006) Thoracoscopic parietal pleural argon beam coagulation versus pleural abrasion in the treatment of primary spontaneous pneumothorax. Eur J Cardiothorac Surg 29(1):6-8

16. Torre M, Grassi M, Nerli FP, Maioli M, Belloni PA (1994) Nd-YAG laser pleurodesis via thoracoscopy. Endoscopic therapy in spontaneous pneumothorax Nd-YAG laser pleurodesis. Chest 106(2):338-341

17. Daddi N, Vannucci J, Maggio C, Giontella A, Bravi I, Marziani F, Capozzi R, Ragusa M, Bufalari A, Puma F (2011) Efficacy of tigecycline pleurodesis: a comparative experimental study. J Surg Res 169(2):e109-e118

18. Vannucci J, Droghetti A, Bufalari A, De Monte V, Bellezza G, Bianconi F, Pecoriello R, Daddi N, Moriconi F, Puma F (2016) Effectiveness and predictability of pleurodesis with the Tachosil ${ }^{\mathbb{R}}$ surgical patch compared with talc poudrage: an experimental study. Eur J Cardiothorac Surg doi:10.1093/ejcts/ezw118 [Epub ahead of print].

19. Lang-Lazdunski L, Chapuis O, Bonnet PM, Pons F, Jancovici R (2003) Videothoracoscopic bleb excision and pleural abrasion for the treatment of primary spontaneous pneumothorax: long-term results. Ann Thorac Surg 75(3):960-965

20. Argote-Greene LM, Chang MY, Sugarbaker DJ (2005) Extrapleural pneumonectomy for malignant pleural mesothelioma. MMCTS (0628), mmcts-2004. doi: 10.1510/mmcts.2004.000133 